http://jmscr.igmpublication.org/home/

ISSN (e)-2347-176x ISSN (p) 2455-0450

crossref DOI: https://dx.doi.org/10.18535/jmscr/v8i6.52

Journal Of Medical Science And Clinical Research

\title{
A Case Report On Van Der Knaap Disease (Vacuolating Megalencephalic Leukoencephalopathy) in Lower Assam of Northeast India
}

\section{Authors}

\section{Dr Vishal Bahadur Chetry ${ }^{1}$, Dr Madhurjya Kumar Thakur ${ }^{2}$, Dr Sangita Mahela ${ }^{3}$}

${ }^{1}$ Post Graduate Trainee, Department of Radiodiagnosis, Fakhruddin Ali Ahmed Medical College and Hospital, Barpeta, Assam

${ }^{2}$ Proffesor and H.O.D, Department of Radiodiagnosis, Fakhruddin Ali Ahmed Medical College and Hospital, Barpeta, Assam

${ }^{3}$ Assistant Professor, Department of Radiodiagnosis, Fakhruddin Ali Ahmed Medical College and Hospital, Barpeta, Assam

\section{Introduction}

$>$ Megaloencephalic leuco-encephalopathy, formally known as Van der Knaap disease, refers to a rare inherited autosomal recessive disease

$>$ Characterized by macrocephaly with diffuse confluent white matter T2/FLAIR hyper-intensity in the sub-cortical white matter.

$>$ Here is a case of megaloencephalic leucoencephalopathy (van der knaap disease) diagnosed on $\mathrm{CT}$ and MRI in FAAMCH in Lower Assam of Northeast India.

\section{Case Report}

- A patient aged 1 year 6 months was brought to the Pediatric OPD with the chief complaints of gradual increase in the size of head for one year, ataxia and mild hearing loss.

- There was no history of any associated fever, seizure or trauma.
- There is no history of such illness in family.

- Peri-natal history was normal

- Developmental milestones were normal

- On examination

- Patient's lower limbs were hypotonic \& had ataxia

- Head Circumference Was 52.5 CM

- Height was $85.3 \mathrm{~cm}$

- Weight was $10.2 \mathrm{~kg}$

Figure -1

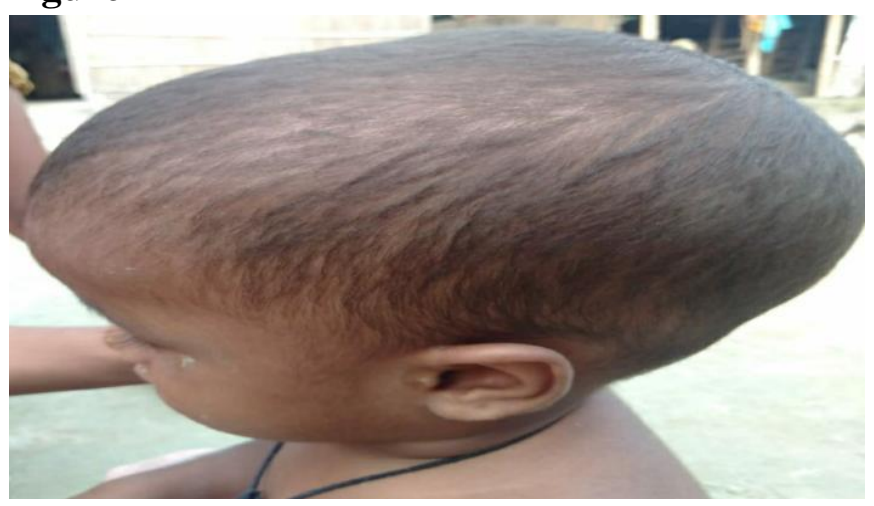

On CT Scan, Diffuse White Matter Hypodensity With Increased Volume of White Matter 


\section{JMSCR Vol||08||Issue||06||Page 271-274||June}

Involving Bilateral Cerebral Hemispheres with Focal Cystic Changes in Bilateral Temporal Lobes Is Noted.

\section{Figure -2}
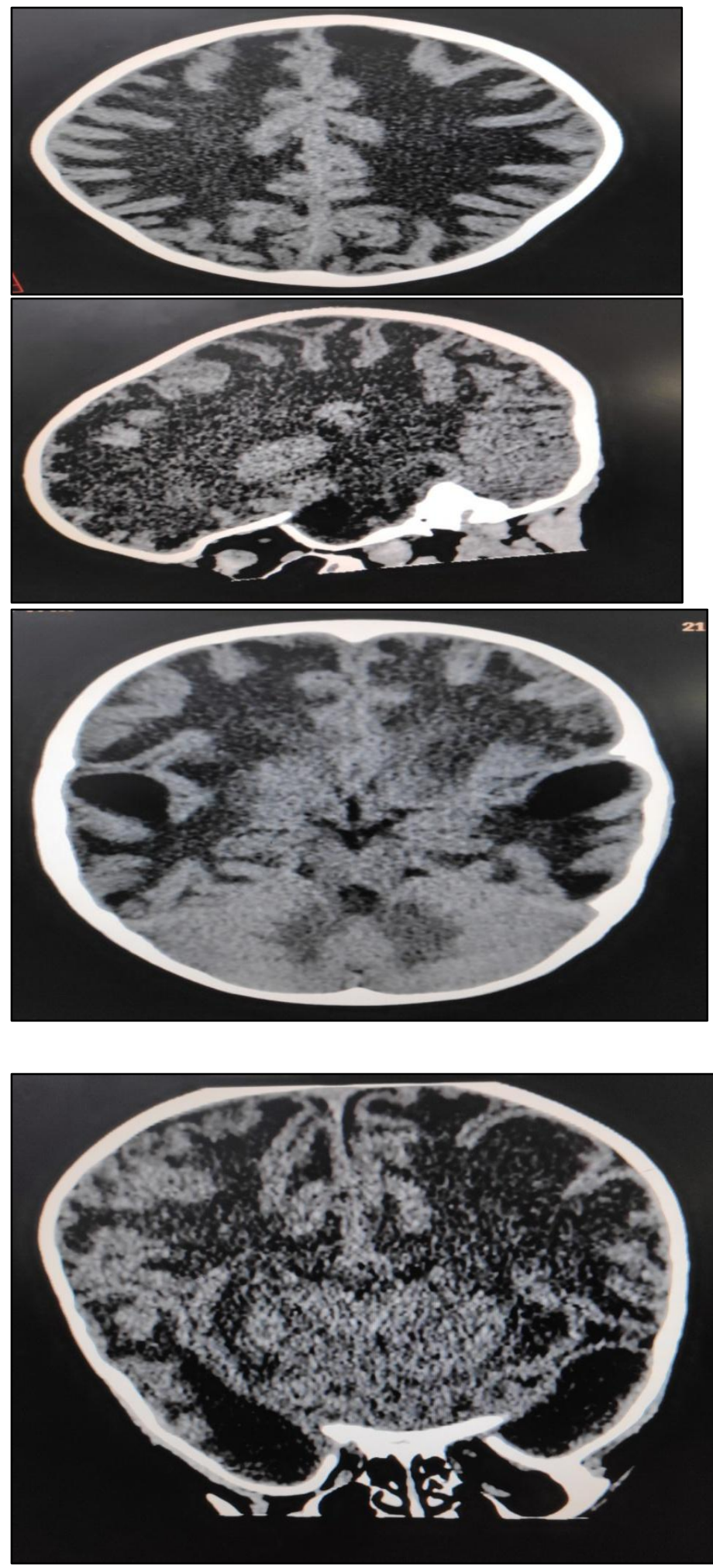

White matter on T1 sequence is hypo-intense with subcortical cysts

Figure -3
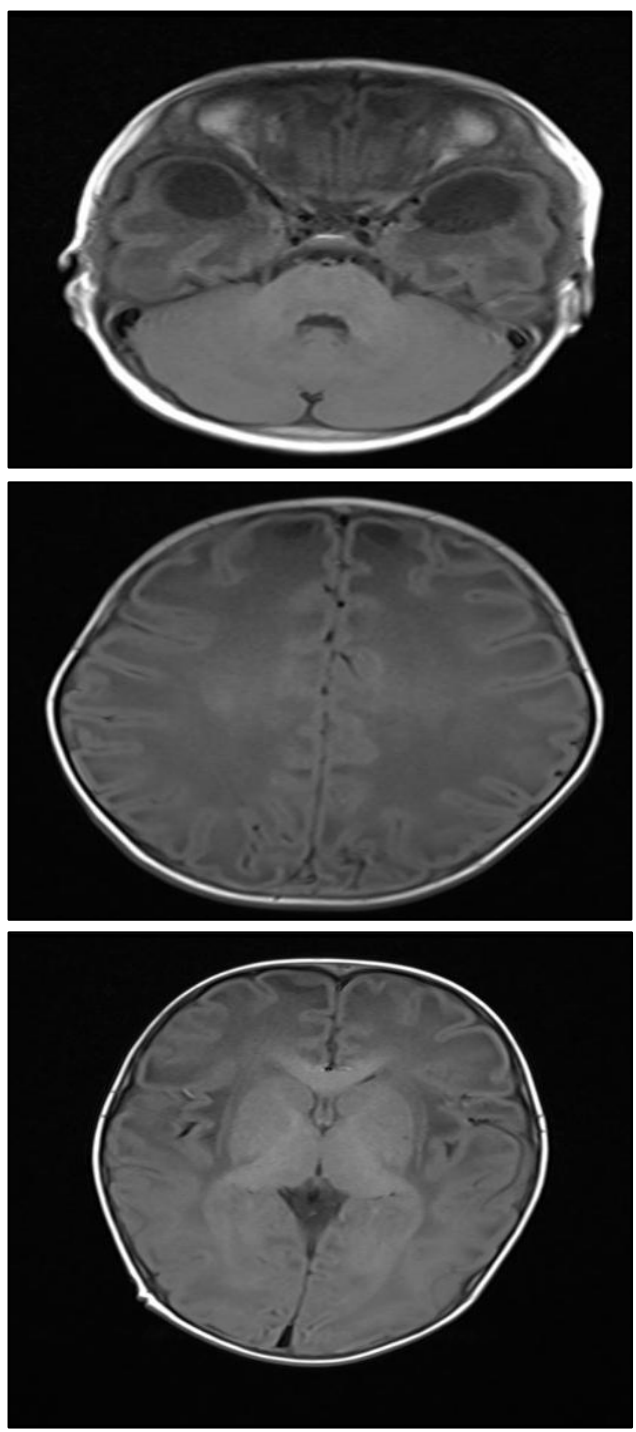

White matter on T2 sequence is hyper intense including the sub-cortical U-fibres

Figure -4

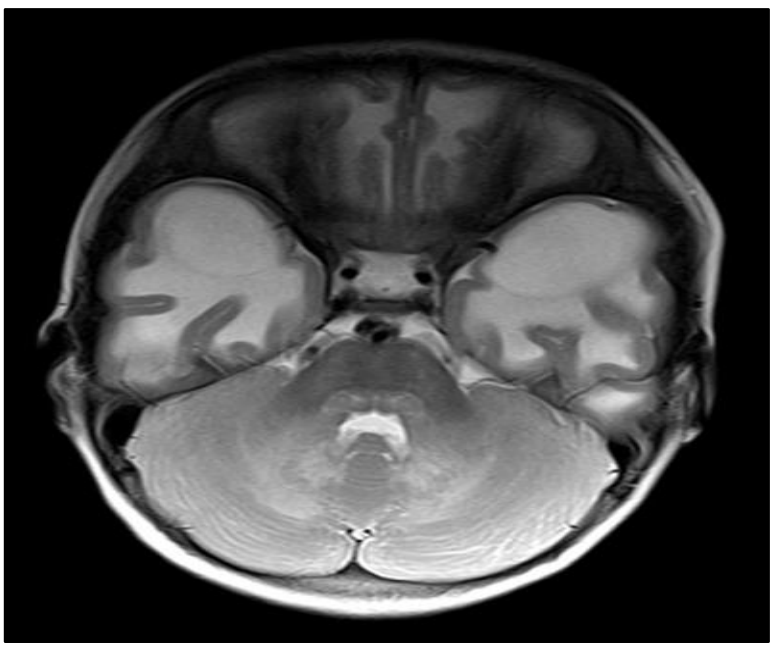




\section{JMSCR Vol||08||Issue||06||Page 271-274||June}

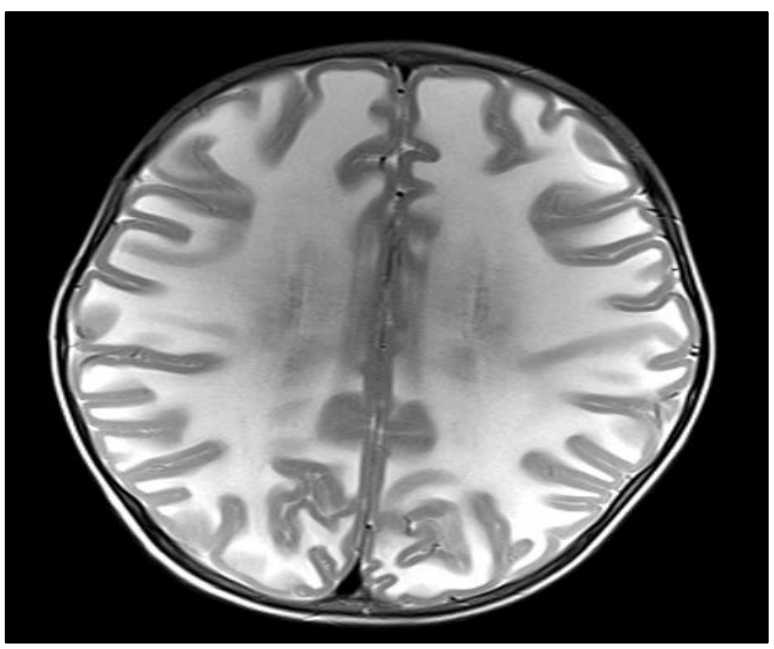

White matter on FLAIR is hyper-intense with subcortical cysts

Diagnosis $\quad-\quad$ Megaloencephalic Leukoencephalopathy With Subcortical Cysts (Van Der Knaap Disease)

Figure -5
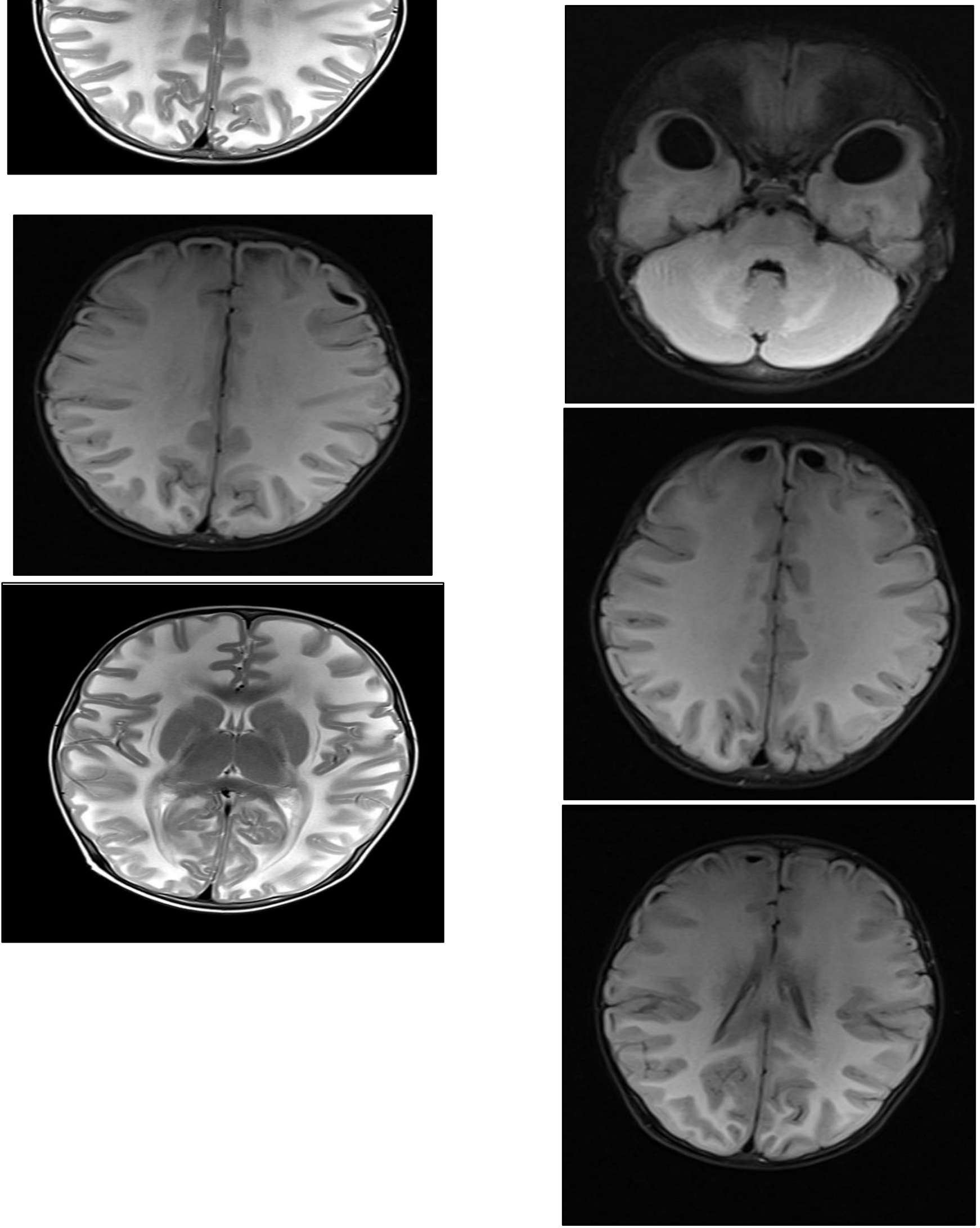


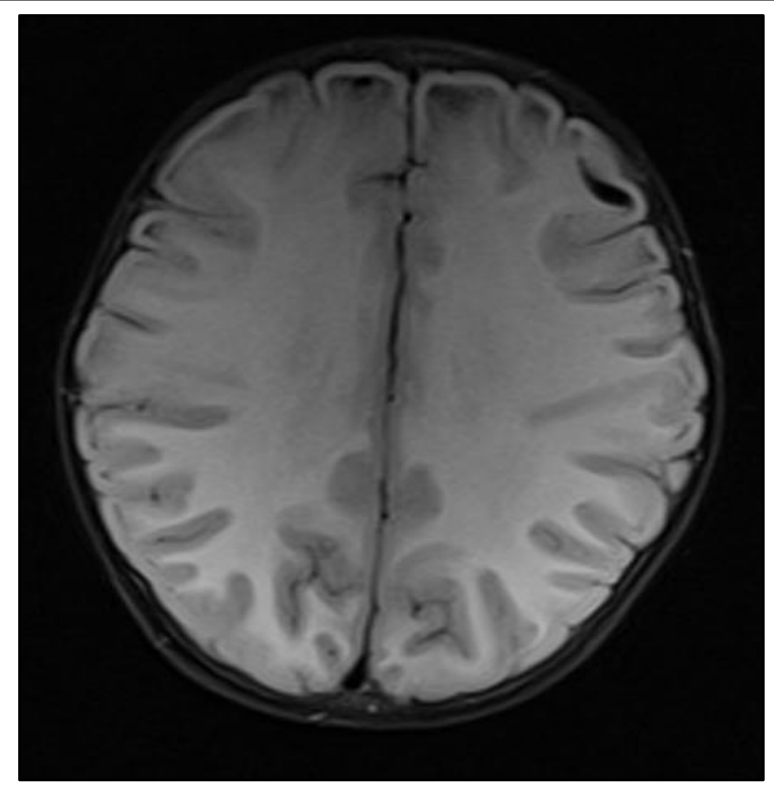

\section{Discussion}

Vacuolating megalencephalic leukoencephalopathy

(VML) (leukoencephalopathy, megalencephaly, and mild clinical course; van der Knaap disease) is a new entity of neurodegenerative disorders characterized by infantile-onset megalencephaly, cerebral leukoencephalopathy, and a delayed onset of slowly progressive neurologic dysfunction. In contrast to the relentlessly progressive infantileonset leukoencephalopathy that is frequently fatal within the first decade of life, such as with Canavan disease, Alexander disease, and GM1 gangliosidosis, VML has the distinguishing feature of a remarkably slow course of deterioration in neurologic function. Neuropathologic appearance of VML is that of a spongioform leukoencephalopathy ${ }^{1}$

Etiology-Approximately $75 \%$ of cases are caused by mutation in the MLC 1 gene located on chromosome 22 (tel). A newly described mutation in the HEPACAM genes account for the remaining cases

Pathology- Gross Pathology- Swollen cerebral hemispheric white matter, relative occipital sparing, variable involvement of sub cortical arcuate fibres, frequent involvement of external capsule and sparing of internal capsule with multiple variable sized sub cortical cysts often involving the temporal lobes the basal ganglia are spared

Histopathology- Extensive vacuolation in the outer layer of myelin sheath accompanying foir the characteristic swollen appearance of the the white matter on MR.

Clinical Features- It is distinguished clinically from other leukoencephalopathy by its remarkably slow course of neurologic deterioration. Infantile onset macrocephaly is characteristic. Median age of onset of prominent clinical symptoms is 6 months.

Pyradimal and cerebellar signs are common .therefore early motor developmental delay, gait ataxia and hypotonia may be observed. Eventually progressive to spastic tetra paresis occurs. Seizures are variable. Cognitive decline occurs as disease progresses.

Differential diagnosis-

1. Alexander disease

2. Canavan disease. ${ }^{2}$

\section{Bibliography}

1. Tu YF, Chen CY, Huang CC, Lee CS. Vacuolating megalencephalic leukoencephalopathy with mild clinical course validated by diffusion tensor imaging and MR spectroscopy. American journal of neuroradiology. 2004 Jun 1;25(6):1041-5.

2. Osborn AG, Salzman KL, Jhaveri MD, Barkovich AJ. Diagnostic imaging: brain E-book. Elsevier Health Sciences; 2015 Dec 24. 